\title{
Utilização do mapeamento do fluxo de valor para a identificação de desperdícios em processos de produção de portas de vagões gôndola
}

Keilane Nieiro Mantovani keilanemantovani@gmail.com

FAESA, Vitória, Espíito Santo, Brasil

Schleiden Pinheiro Nascimento schleidenn@gmail.com

FAESA, Vitória, Espírito Santo, Brasil

\begin{abstract}
RESUMO
Para tornarem processos mais eficazes, produtivos e garantirem a satisfação do cliente, empresas tem adotado estratégias que permitem otimização dos seus recursos tornandoas mais sólidas e competitivas em meio a diversas crises econômicas. Portanto, na busca desses objetivos e para sua própria sobrevivência, tem - se implantado nas culturas organizacionais o Lean Manufacturing. Essa filosofia tem se tornado um grande diferencial nas empresas, uma vez que consiste em reduzir e eliminar desperdícios através das atividades que agregam ou não valor ao sistema. O objetivo deste trabalho é identificar e descrever os desperdícios no processo de produção de portas de vagões gôndola, em uma Oficina de Manutenção de Vagões, a partir da ferramenta de manufatura enxuta: Mapeamento do Fluxo de Valor (MFV). O procedimento metodológico consistiu de uma descrição do processo de produção de portas de vagões gôndola, a partir de entrevistas com colaboradores e observação de uma oficina. Após mapeamento do fluxo de valor para o processo, foram identificados os desperdícios gerados, sendo proposto um novo fluxo de valor com melhorias para aumento de produtividade. Os resultados apontaram uma melhoria significativa no processo produtivo, com redução do Lead Time em $70 \%$ e tempo de processamento em $25 \%$. Diante desses resultados, o Lean Manufacturing vai ao encontro das novas exigências do mercado, que buscam otimizar os recursos existentes, de forma a atender o cliente no menor prazo, com alta qualidade e custos baixos. 0 trabalho conclui que a implantação da metodologia propicia ganhos reais de desempenho e financeiros para as empresas.
\end{abstract}

PALAVRAS-CHAVE: Lean Manufacturing. Mapeamento de Fluxo de Valor. Eliminação de desperdícios. 


\section{INTRODUÇÃO}

O mercado passa por transformações que forçam um novo contexto dinâmico para as organizações. Cada vez mais os produtos têm que competir em preço e qualidade com os seus concorrentes que muitas vezes vêm de países com elevado nível de desenvolvimento tecnológico ou de países onde os custos de fabricação estão em um patamar mais baixo (SALGADO et al., 2009).

Para obter êxito nesse mercado atual, empresas estão reavaliando suas estratégias, buscando novas práticas de atuação e promovendo grandes transformações da maneira mais eficiente. Têm sido diferenciais dessas empresas dinâmicas a busca por realização de mudanças na gestão, melhoria de processos, redução de custos e eliminação de desperdícios.

Para a evolução dos sistemas organizacionais, faz-se necessária a implantação de metodologias que possibilitem descobrir as dificuldades existentes nos processos, identificando os gargalos e atuando sobre eles. Um dos métodos que pode ser utilizado é o Lean Manufacturing, que possui um modelo mental enxuto, cuja base é formada pela estabilidade e padronização dos processos, com a finalidade de reduzir desperdícios e aumentar a produtividade.

O Lean Manufacturing baseia-se em esforços para eliminação de desperdícios e em atividades que não agregam valor aos olhos do consumidor e que possam ser otimizados ou eliminados através da aplicação de conceitos e ferramentas. A base do conceito de produção enxuta está na diminuição dos custos sob o ponto de vista do cliente final. No processo produtivo é necessário definir o que é valor, isto é, o que o cliente está disposto a pagar pelo produto final (ROYER; FERREIRA; SAVEDRA, 2018).

$\mathrm{Na}$ filosofia Lean, uma ferramenta muito utilizada para identificar os fluxos existentes dentro de um processo de um produto ou serviço é o MFV (Mapeamento do Fluxo de Valor). Essa ferramenta permite visualizar o processo como um todo, permitindo-se identificar os diversos tipos de desperdícios existentes e suas fontes dentro do fluxo, direcionando a escolha do melhor caminho e a possível tomada de decisão em relação ao fluxo de atividades.

O foco dessa pesquisa foi em uma companhia de soluções logísticas integradas que interliga ferrovias, terminais e portos. A área explorada fica em uma ferrovia desta empresa, especificamente em uma de suas oficinas de manutenção de vagões. $O$ estudo está concentrado no processo produtivo de portas de vagões gôndola, na fábrica de Caldeiraria dessa oficina.

Devido a inexistência de planejamento e programação de produção dessa fábrica, a variabilidade de produção e estoques de matéria-prima, é alto. Dificuldade de movimentação entre as máquinas, estoque em processo, e um arranjo físico disperso, são itens que podem influenciar o fluxo produtivo do produto. Portanto, tem-se uma questão para direcionar o estudo: Quais os desperdícios existentes no processo de produção de portas de vagões gôndola que impedem a maior produtividade nas atividades?

Tomando como verdade que os desperdícios afetam de forma significativa a produtividade nos processos de produção de portas de vagões gôndola, esse estudo tem como objetivo geral identificar e descrever os desperdícios no 
processo de produção de portas de vagões gôndola a partir da ferramenta de Mapeamento do Fluxo de Valor (MFV).

Os objetivos específicos desse estudo foram: Descrever o processo de produção de portas de vagões gôndola, mapear o fluxo de valor para o processo, identificar os desperdícios gerados, mapear um novo fluxo de valor e propor melhorias para aumento de produtividade.

Este estudo se justifica por analisar falhas na entrega do produto para seu cliente (processo de manutenção de vagões) uma vez que esse item é um dos inputs para o processo. A fábrica não possui controle de produção ordenado e sistematizado, além de ter um layout extenso para o seu fluxo produtivo. Como não há uma estruturação, o negócio apresenta baixa eficiência e pouca ou quase nenhuma conectividade, fazendo com que haja desperdícios de recursos. Pretende-se fornecer com esse estudo contribuições para processos e ou empresas que passam pelo mesmo desafio e que para sobreviverem e se manterem competitivas, necessitam mudar seu sistema organizacional.

\section{METODOLOGIA}

Foi realizada uma pesquisa indutiva, que analisa o particular para o geral, onde será possível verificar as relações quantitativas das variáveis envolvidas.

O estudo é uma observação do processo produtivo de portas de vagões gôndola em área fabril, além de obtenção e análise dos dados referentes a este processo da companhia, sendo, portanto, considerada como pesquisa de campo com fontes primárias.

A pesquisa é classificada quanto a sua natureza como aplicada, pois objetiva gerar conhecimento para aplicação prática e solução de problemas da empresa. Quanto à sua abordagem ela é qualitativo-quantitativa, pois interpreta e colhe as informações e dados em campo e traduz em números as opiniões e informações para serem classificadas e analisadas. Quanto aos objetivos é caracterizada como uma pesquisa descritiva, pois os fatos são observados, registrados, analisados e interpretados sem a interferência da pesquisadora. Por fim, quanto aos procedimentos teóricos é classificado como estudo de caso, pois envolve um estudo aprofundado do processo de fabricação de portas dos vagões gôndola em um caso específico.

Portanto, esse estudo de caso foi realizado em uma oficina de manutenção de vagões, na fábrica de caldeiraria, de uma empresa de grande porte na área de logística, no Brasil.

A observação direta e assistemática foi realizada na planta industrial da empresa, de forma espontânea nas operações da fábrica de caldeiraria, onde foi possível diagnosticar que o principal produto da fábrica era a produção de portas de vagões gôndola, que além de possuir processos desordenados, como por exemplo layout amplo e matéria prima espalhadas no chão da fábrica, havia oscilações no atendimento do produto ao principal cliente, que estava localizado na mesma planta fabril. Portanto, definiu-se que esse seria o processo/produto estudado e analisado.

Foram entrevistados profissionais operacionais (ao todo 10 mecânicos) e estratégicos (4 empregados do Planejamento e Controle da Manutenção), sendo 
todos envolvidos diretamente na realização das atividades do processo de fabricação de portas de vagões gôndola. Dessa forma, a base de dados utilizada nesse estudo fora oriunda de entrevistas, observações in loco e dados em planilhas eletrônicas. Segundo Yin (2009), citado por Ruiz, Mendes, Silva (2015), a observação direta e as entrevistas são fontes de evidência para o fenômeno a ser analisado no estudo de caso. Além disso, Hancock e Algozzine (2006) citam que através de estudos de caso, os pesquisadores esperam ganhar uma compreensão profunda das situações e significado para os envolvidos.

As entrevistas foram realizadas com o apoio de um roteiro contendo a lista de cada peça que era fabricada em cada máquina que estava presente no processo produtivo. Logo, foi possível mapear todo o processo e anotados os tempos de produção de cada peça. Outra fonte de dados utilizada nesse estudo foi a observação indireta de registros de produção e acompanhamentos de produção do grupo operacional da empresa. Esses registros proporcionaram um entendimento maior dos procedimentos, métodos, ferramentas e técnicas utilizadas pelos operadores da área.

Com base no levantamento de dados e com a utilização do Microsoft Visio, foi possível mapear processos atuais através do MFV (Mapeamento do Fluxo de Valor). Diante do MFV, são apresentados os fluxos de informações e materiais básicos do processo de fabricação de portas de vagões gôndola, permitindo o aumento da visibilidade da cadeia e questionamentos das práticas adotadas.

Assim, foi observada e analisada toda a operação, o que permitiu identificar as atividades que agregam valor, as que não agregam valor, mas são necessárias e as que não agregam valor, ou seja, os desperdícios.

A partir da análise, foi proposto um novo MFV, para o estado futuro, com o objetivo de otimizar os processos, eliminando os desperdícios observados.

\section{PRODUÇÃO ENXUTA E MAPEAMENTO DO FLUXO DE VALOR}

O Lean Manufacturing surgiu após a segunda guerra mundial. Naquela ocasião os japoneses da Toyota sentiram a necessidade de reorganizar seu parque industrial, com a finalidade de otimizar a utilização de seus poucos recursos produtivos para competir com a indústria de veículos norte americana. Foi necessária uma nova forma de gestão produtiva que propiciasse a redução de seus custos e os permitisse competir com os altos índices de produtividade gerados pelos grandes volumes de produção dos EUA. Para compensar a baixa escala de fabricação, lançaram-se firmemente no propósito de reduzir os custos totais de produção, eliminando desperdícios de produzir bens com valores não reconhecidos pelos clientes (WOMACK; JONES; ROSS, 2004).

O processo de enxugamento ficou conhecido no ocidente por lean manufacturing (manufatura enxuta). A filosofia Lean, por ter sido primariamente desenvolvida na Toyota, também é conhecida como Sistema Toyota de Produção, ou simplesmente STP (CATAPAN et al, 2013).

A finalidade do Lean Manufacturing é realizar as necessidades do cliente, oferecendo serviços e produtos de elevada qualidade, com o menor custo e lead time possível, além de proporcionar um ambiente de trabalho seguro, um clima organizacional agradável, elevando assim a moral dos seus colaboradores. 0 
principal objetivo do Lean é a maximização dos lucros através da redução dos custos. (GUTERRES, et al.,2017)

O Lean é uma estratégia de negócios para aumentar a satisfação dos clientes através da melhor utilização dos recursos. A gestão Lean procura fornecer, consistentemente, valor aos clientes com os custos mais baixos, através da identificação de melhoria dos fluxos de valor primários, e de suporte, por meio do envolvimento das pessoas qualificadas, motivadas e com iniciativa (LEAN MANUFACTURING, 2012).

De acordo com Pires et al. (2012), o que evidencia a base de sustentação do Lean Manufacturing é a eliminação total dos desperdícios, além das principais características da metodologia, bem como seus dois pilares, o Just in Time ou JIT, e a Autonomação ou Jidoka - entre outros componentes essenciais do sistema como pode ser visto na figura 1:

Figura 1: Casa do Sistema Toyota de Produção

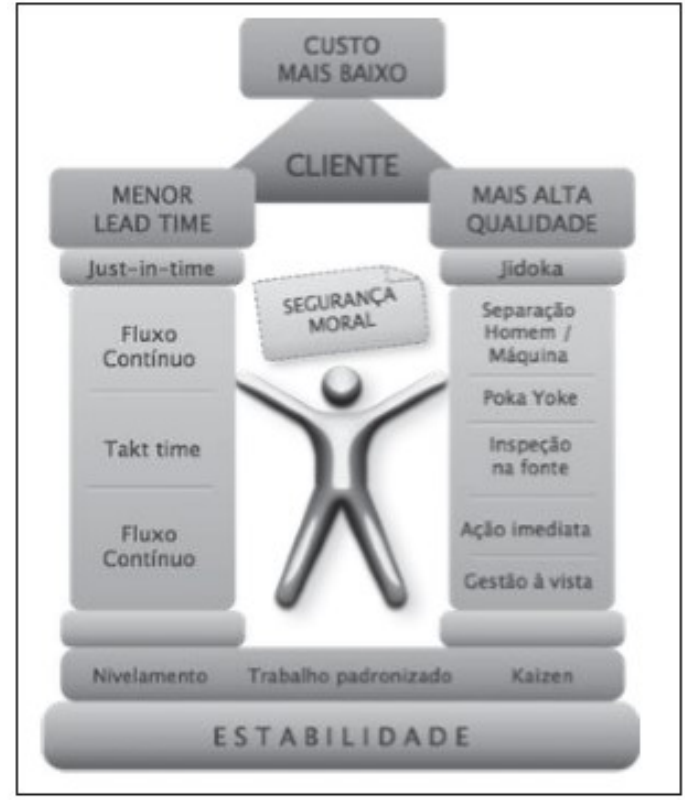

Fonte: Pires et al. (2012)

De acordo com Dennis (2008) a base do sistema Lean é estabilidade e padronização. As paredes são a entrega de peças e produtos just in time e jidoka, a autonomação com uma mente humana. A meta (o telhado) do sistema é o foco do cliente (...). O poder do sistema Toyota está no constante reforço de seus conceitos centrais.

Segundo Ohno (1997) citado por Pires et al. (2012, p.4) o Just in Time significa "no momento oportuno", ou seja, refere-se às entregas aos clientes, no tempo certo e quantidades pedidas, sem gerar estoques ou atrasos, que implicam diretamente na produtividade e na lucratividade. E o Jidoka significa a transferência da inteligência humana para uma máquina. Dessa forma, o próprio sistema pode identificar possíveis anormalidades no processo e parar o seu funcionamento. A vantagem da autonomação é conseguir manter um sistema à prova de erros, evitando desperdícios com produtos defeituosos e com superprodução. 
Segundo Moraes et al (2011), a Toyota identificou os 7 principais desperdícios comumente encontrados em processos produtivos:

a) Superprodução ou produção em excesso: Produção antecipada ou excessiva (acima da demanda). Gera excesso de pessoal, excesso de estoque e transporte desnecessário. Tem a propriedade de esconder outras perdas;

b) Excesso de estoque: Excesso de matéria-prima, de estoque em processo ou produto acabado. Caracteriza dinheiro parado, que ainda gera custo excessivo, baixo desempenho do serviço prestado ao cliente, longo lead time, produtos danificados e atrasos. Oculta problemas como desbalanceamento de produção, defeitos no produto ou em equipamentos e longo tempo de setup;

c) Defeitos: Problemas de qualidade, retrabalhos e descarte. Geram custos de recuperação ou perda total de material e tempo, havendo risco de perda de confiança do cliente caso o defeito não seja detectado;

d) Espera: Ociosidade de pessoas, informação, matéria-prima ou produto semiacabado. Pode ter basicamente as seguintes causas: espera por um processamento atrasado; espera de processamento de todas as peças do lote; espera por falta de estoque; espera por uma ferramenta; e espera gerada quando o funcionário é forçado a permanecer junto à máquina para vigiá-la ou devido ao desbalanceamento das operações. Gera longo lead time;

e) Transporte desnecessário: movimento de estoque por longas distâncias ou transporte ineficiente. Em empresas de produção de bens é uma atividade que não agrega valor e deve ser minimizada, pois despende capital, tempo e energia. Mudanças simples de layout diminuem a necessidade de transporte;

f) Movimentação desnecessária: movimentos que o funcionário tem que fazer para procurar, pegar ou empilhar. Está relacionado à desorganização do ambiente, gera perda de tempo e pode ser eliminado através do estudo de tempos e movimentos ou modificação de layout;

g) Superprocessamento ou processamento incorreto: Processamento desnecessário ao valor que o cliente deseja ou processamento inadequado. Causa movimentos desnecessários, perdas de tempo e esforço e ainda pode produzir defeitos. Produto com qualidade superior a esperada pelo cliente é considerado desperdício.

Riani (2006) relaciona os sete tipos de desperdícios classificando-os por pessoas, quantidade e qualidade, conforme figura 2 : 
Figura 2: Sete Tipos de Desperdícios

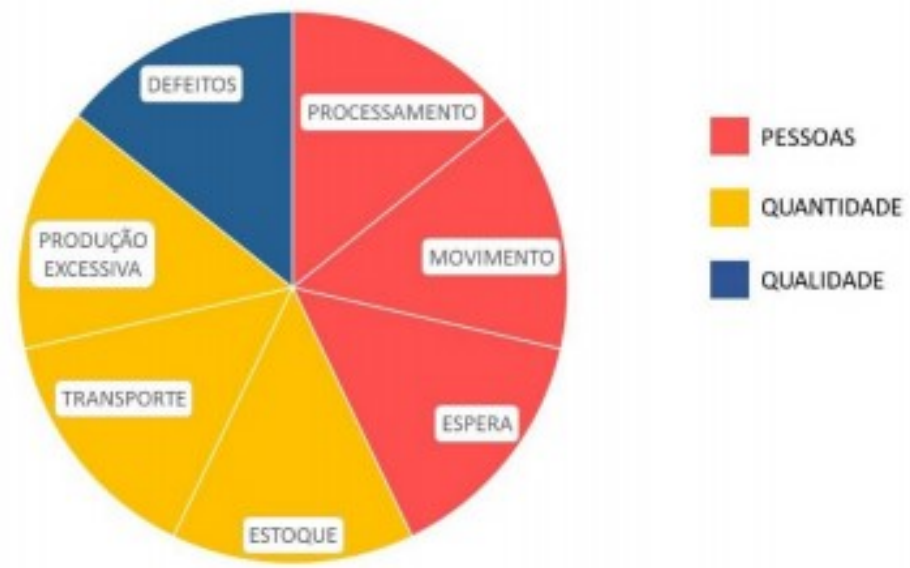

Fonte: Riani, A. M. (2006)

Segundo Womack, Jones e Ross (2004) e Satolo (2011) citados por Ribeiro Junior, Rodrigues e Ribeiro (2012), a mentalidade Enxuta se baseia em cinco princípios básicos para combater tais desperdícios:

a) Valor, o qual deve sempre ser especificado pelo cliente;

b) Cadeia de Valor, que são todas as etapas ligadas às tarefas de concepção e lançamento de um produto, gerenciamento da informação e transformação física;

c) Fluxo, que se refere à eliminação total das paralizações em todos os processos de produção;

d) Produção Puxada, onde o cliente é o único responsável pelo andamento do processo produtivo;

e) Perfeição, a qual surge por meio da exposição contínua dos desperdícios, através de transparência e feedback constantes.

Segundo Ohno (1997), Slack et al. (2009), Salgado et al. (2009) e Corrêa e Corrêa (2004) citados por Oliveira et al. (2015), muitas ferramentas são utilizadas para o bom funcionamento do sistema Lean Manufacturing. Porém as mais conhecidas e de uso contínuo são:

a) Andon: é um quadro indicador encontrado no chão de fábrica que aponta se há um problema na linha de produção;

b) Poka-Yoke: significa "a prova de erros". São dispositivos ou ações simples que tem como objetivo eliminar os erros ou corrigi-los antes que se tornem defeitos;

c) Kanban: significa "cartão". São instruções colocadas nas peças que devem ser passadas ao longo do fluxo de material, contribuindo para o sistema puxado;

d) Kaizen: traduzido como "melhoria contínua". Filosofia que busca o aprimoramento do conhecimento e desempenho;

e) $5 \mathrm{~S}$ : visa manter o ambiente de trabalho em ordem. Cada " $\mathrm{S}$ " faz referência a uma palavra em japonês: seiri, seiton, seiso, seiketsu e shitsuke, que significam, 
respectivamente, liberação de áreas, organização, limpeza, padronização e disciplina;

f) Total Productive Maintenance (TPM): visa eliminar a variabilidade em processos de produção, a qual é causada pelo efeito de quebras não planejadas;

g) Value Stream Map (VSM): é uma ferramenta que auxilia na identificação nas atividades que agregam e que não agregam valor ao processo;

h) Diagrama de Ishikawa (Causa e Efeito): busca identificar possíveis causasraízes de um problema;

i) Failure Mode and Effect Analysis (FMEA): tem como função identificar recursos que são críticos e que podem gerar falhas, a fim de priorizar ações de prevenção e correção;

j) Cinco Por quês: quando ocorre alguma falha, responde-se cinco vezes à pergunta "por quê?" para, assim, encontrar a causa-raiz.

k) Ciclo PDCA: o ciclo Plan-Do-Check-Act é a sequência de atividades que são percorridas de maneiras cíclicas para melhorar processos.

Define-se fluxo de valor da produção como toda ação necessária para fabricar um produto, ou uma família de produtos, desde a aquisição da matéria prima até a entrega ao consumidor final (ROTHER e SHOOK, 1999).

Assim, o Mapeamento do Fluxo de Valor (MFV) é uma ferramenta do sistema de produção enxuta que permite enxergar como os fluxos de valores, informação e materiais fluem de porta-a-porta, e quais áreas do fluxo devem ser melhoradas, dessa forma, sendo possível obter ganhos em termos de redução do lead time de produção em processos contínuos. (ROTHER, SHOOK, 1999; TEIXEIRA, ELIAS, TUBINO, 2010; ABDULMALEK, RAJGOPAL, 2007).

\section{APRESENTAÇÃO E ANÁLISE DOS DADOS}

\section{ESTUDO DE CASO}

\section{A empresa e o produto}

O estudo de caso foi realizado em uma empresa de soluções logísticas integradas que interliga ferrovias, terminais e portos. É uma empresa brasileira organizada em holding. Está presente em nove estados brasileiros e no distrito federal. A área explorada fica em uma ferrovia desta empresa, especificamente em uma oficina de manutenção de vagões.

Nesta oficina existem 5 fábricas internas (Caldeiraria, Truque, Tremonha, Freio e Rodeiro) onde são fabricados componentes para a manutenção dos vagões ferroviários. A fábrica escolhida é a Caldeiraria, onde seu portfólio é composto por diversos tipos de produtos cadeirados, entre eles portas de vagões gôndola, reforço para todos os tipos de vagões, fueiros para vagões plataformas, tampas para tetos de vagões graneleiros e outros. Trata - se de uma fábrica muito dinâmica. 
Este estudo está concentrado no processo produtivo de portas de vagões gôndola, sendo justificado por ser o principal produto produzido desta fábrica, que além de possuir processos desordenados, como por exemplo layout amplo e matéria prima espalhadas no chão da fábrica, havia oscilações no atendimento do produto ao principal cliente.

O propósito foi identificar quais são os desperdícios gerados na produção de portas de vagões gôndola segundo os 7 desperdícios encontrados a partir da metodologia Lean Manufacturing.

Assim como qualquer processo produtivo tem - se inputs, processamento e output. Os inputs desse processo são chapas de aço que são inseridas nas máquinas Guilhotina e Pantógrafo. Essas máquinas processam a matéria prima e enviam para as máquinas Dobradeira e Furadeira respectivamente. Após o novo processamento as peças produzidas são enviadas para a bancada de solda, onde são soldadas e transformadas em portas de vagões gôndola conforme pode ser visto abaixo na figura 3 :

Figura 3: Processo produtivo de portas de vagões gôndola

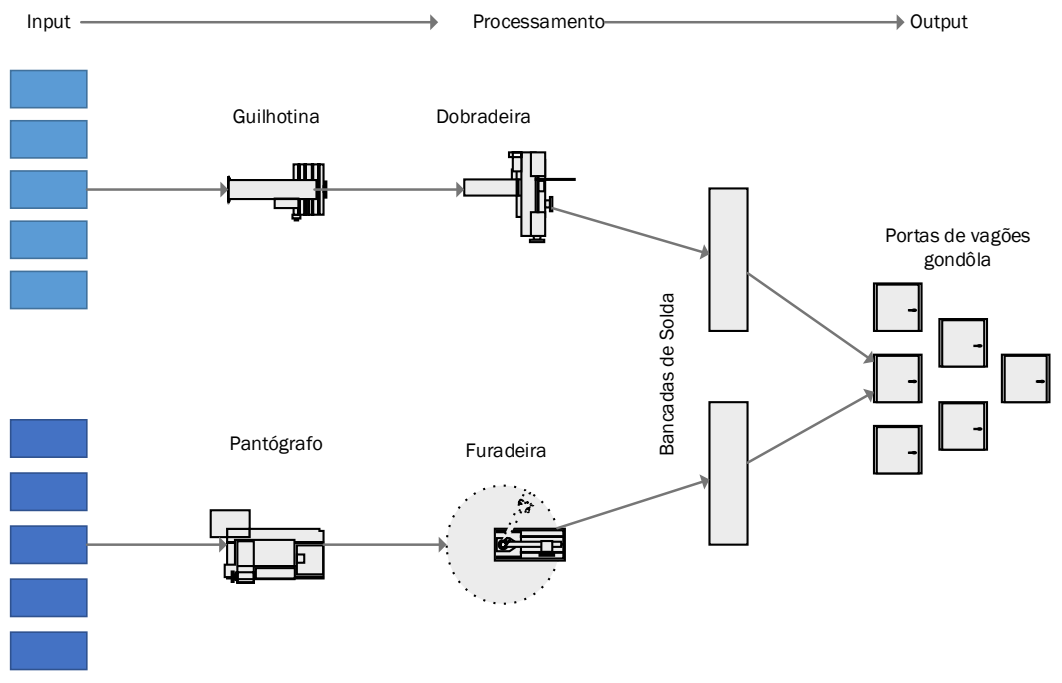

Fonte: Elaborado pelos autores

\section{Layout do site}

A Fábrica de Caldeiraria possui um layout divido em dois ambientes. $\mathrm{O}$ primeiro espaço fica do lado direito da oficina e o segundo ambiente fica do lado esquerdo, conforme pode ser visto na figura 4 : 
Figura 4: Layout da oficina de manutenção de vagões

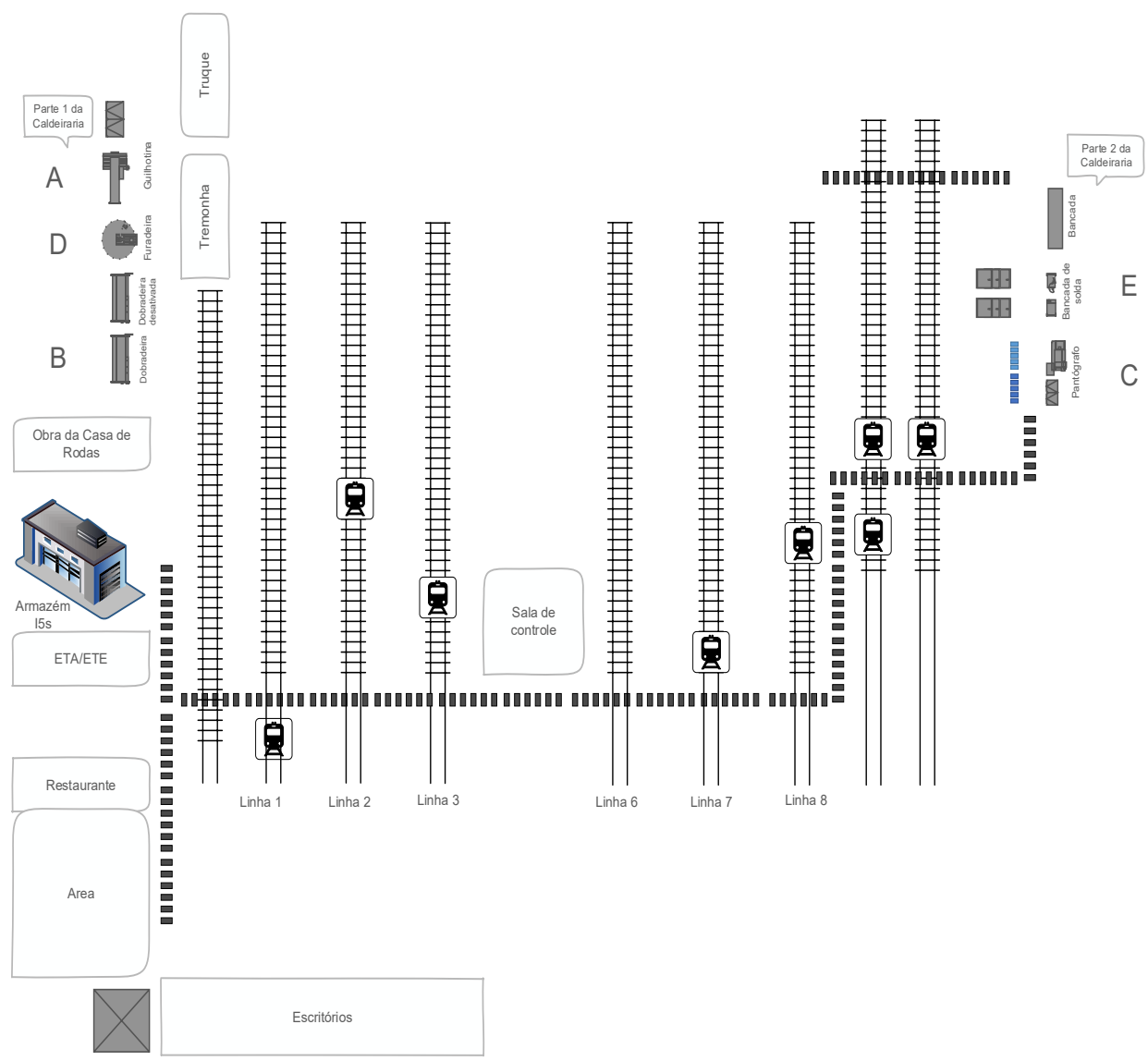

Fonte: Elaborado pelos autores

\section{Mapeamento do fluxo de valor da situação atual}

Para identificar os desperdícios e entender melhor a capacidade produtiva foi elaborado o Mapeamento do Fluxo de Valor (MFV), por meio de levantamento de informações na área de execução, bem como entrevistas com os responsáveis pela gestão de estoques, programadores de produção, e colaboradores do chão de fábrica, a fim de identificar o estado atual. Também foram realizadas cronoanálise do processo.

Com base nos dados e informações coletados foi possível elaborar o mapa de fluxo de valor do estado atual, conforme pode ser visto na figura 5: 


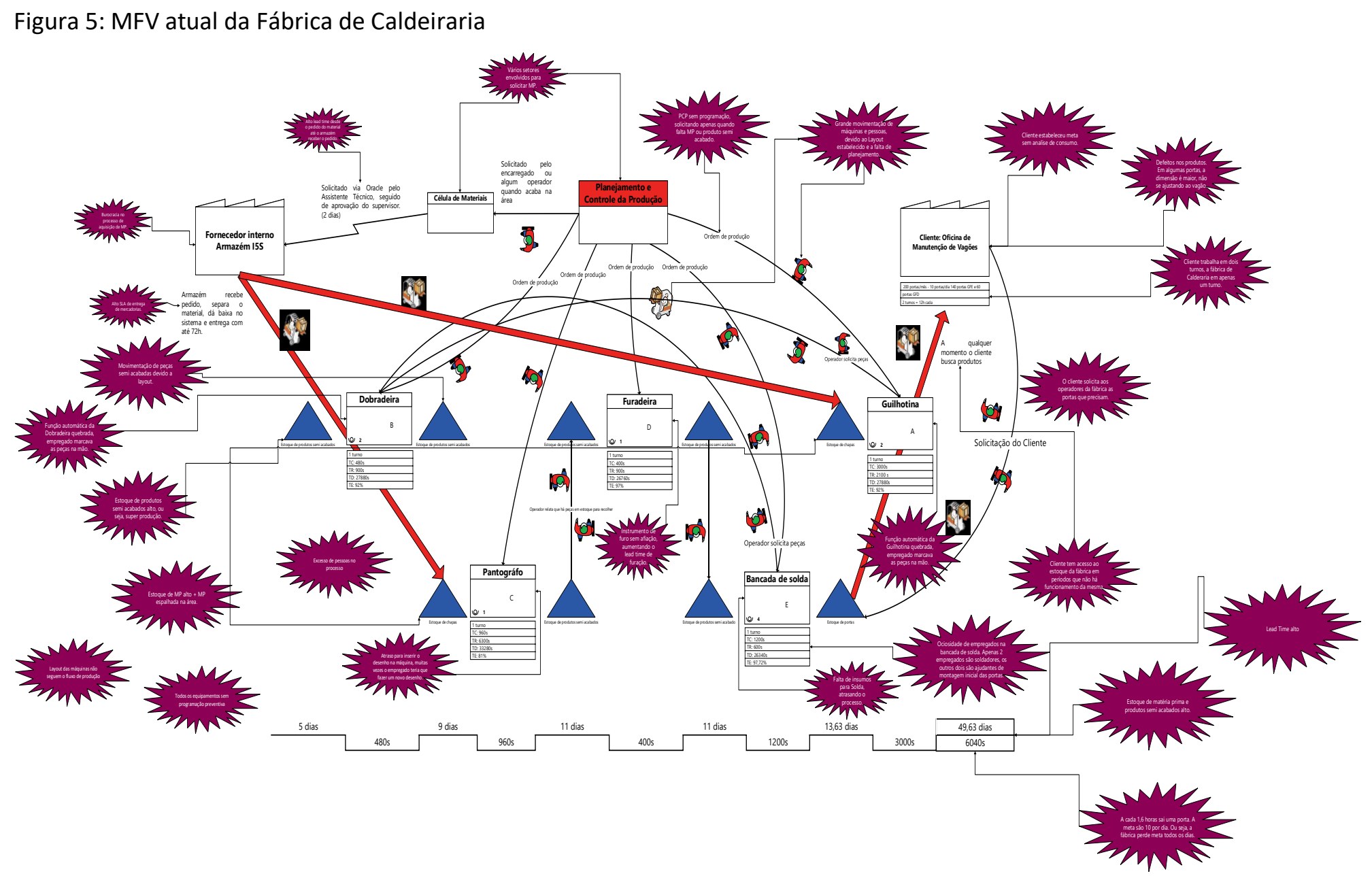

Fonte: Elaborado pelos autores 


\section{Identificação de desperdícios e propostas de melhoria}

Após conclusão do Mapeamento do fluxo de valor atual, foi identificada a ocorrência de 26 desperdícios que causam impacto negativo no processo. 0 Quadro 1, mostra a classificação, a quantidade de defeitos segundo os 7 desperdícios da filosofia Lean e a porcentagem correspondente a eles.

Quadro 1-Classificação de defeitos existentes no MFV atual

\begin{tabular}{|c|c|c|c|c|}
\hline Classificação & Defeitos & Quantidade & $\%$ & $\%$ \\
\hline \multirow{3}{*}{ Pessoas } & Espera & 8 & $31 \%$ & \multirow{3}{*}{$62 \%$} \\
\hline & Movimentação desnecessária & 4 & $15 \%$ & \\
\hline & Processamento Incorreto & 4 & $15 \%$ & \\
\hline Qualidade & Defeitos & 5 & $19 \%$ & $19 \%$ \\
\hline \multirow{4}{*}{ Quantidade } & Excesso de estoque & 2 & $8 \%$ & \multirow{3}{*}{$19 \%$} \\
\hline & Superprodução & 2 & $8 \%$ & \\
\hline & Transporte desnecessário & 1 & $4 \%$ & \\
\hline & Total & 26 & & \\
\hline
\end{tabular}

Fonte: Elaborado pelos autores

Desses desperdícios, $62 \%$ são classificados na dimensão de análise pessoas, $19 \%$ por qualidade e $19 \%$ por quantidade, conforme pode ser visto na figura 6 :

Figura 6 - Visão geral dos defeitos existentes no MFV atual

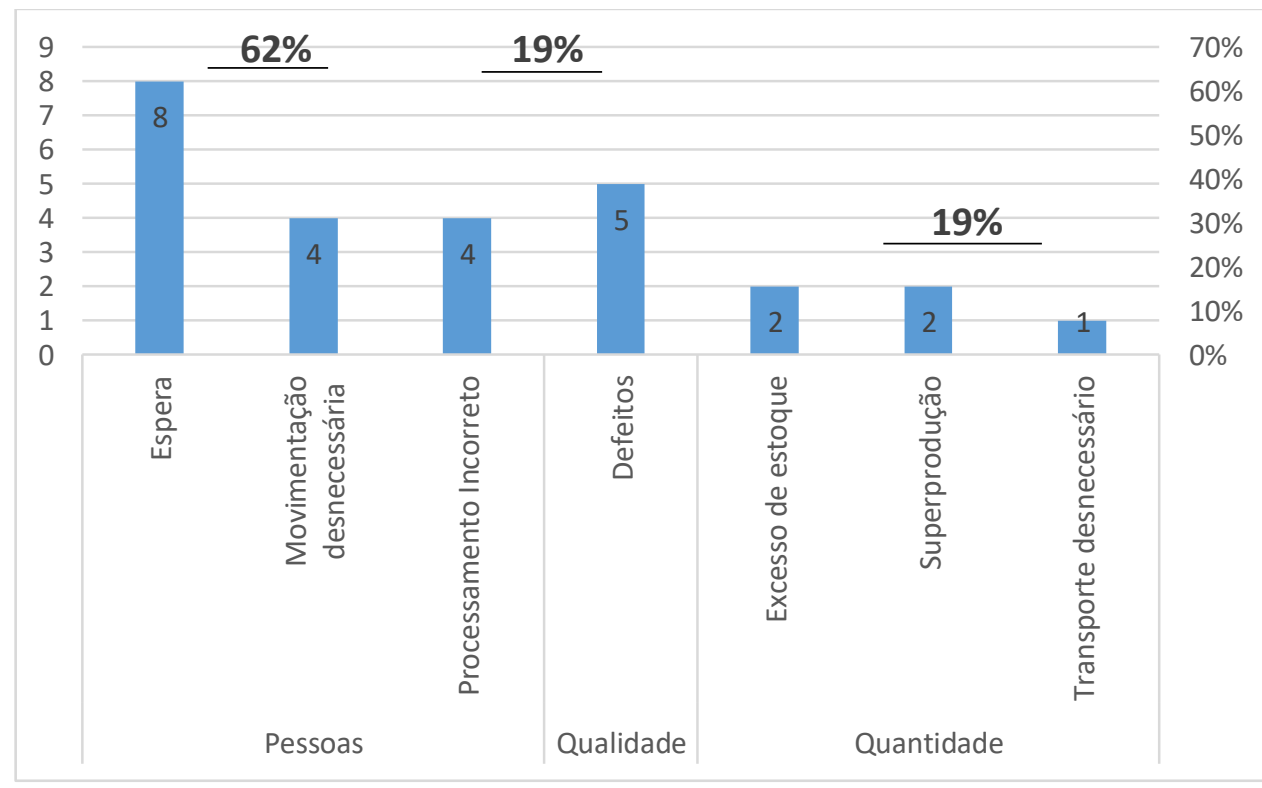

Fonte: Elaborado pelos autores

Analisando o gráfico 1, é perceptível que 31\% dos defeitos encontrados estão relacionados a espera, ou seja, esse defeito é caracterizado por gerar um longo lead time no processo. É preciso inserir programação na fábrica por 
equipamento, inserir programação de solicitações de matéria prima em paralelo com a programação da fábrica e fazer uma análise de produtividade por postos de trabalho a fim de verificar a quantidade de pessoas necessárias para aquele posto.

O desperdício de Movimentação foi responsável por 15\% dos defeitos encontrados. Por estar relacionado ao layout do ambiente, faz - se necessário, uma reorganização do ambiente físico em pararelo a inserção de programação já citada no desperdício de espera.

Além disso, $15 \%$ dos desperdícios gerados estão relacionados ao processamento incorreto, que são causados por movimentos desnecessários, perdas de tempo e esforço. É necessário mapear as atividades que possuem valor, as que não possuem, e as que não possuem, mas são necessárias.

Problemas de qualidade, retrabalhos e descarte representam 19\% dos desperdícios gerados. Faz - se necessário montar um plano de manutenção e um plano inspeções de qualidade nos 5 equipamentos responsáveis pela produção.

Excesso de matéria prima e superprodução correspondem juntos a $16 \%$ dos desperdícios gerados, 8 \% cada. Para o primeiro faz - se necessária revisão das compras dos insumos atrelada a programação da fábrica, recomendável utilizar a filosofia JIT. Para o segundo, atrelado ao desperdício de espera, rever a produtividade dos postos de trabalho; em seguida entender melhor a demanda do cliente aplicando filosofia JIT.

Com 4\%, o desperdício de transporte desnecessário está ligado ao layout do site. Atrelado ao desperdício de espera, faz - se necessária a revisão do layout da fábrica.

\section{Mapeamento do novo fluxo de valor}

Tendo identificado os desperdícios presentes no MFV atual, foi pensado em um novo MFV da fábrica de caldeiraria. Um novo layout foi construído para simplificar o sistema, e implementado o planejamento e programação da fábrica, reduzindo assim o lead time, o tempo de processamento e a quantidade de desperdícios encontrados no MFV atual. Abaixo, na figura 7, encontra - se o layout proposto para o site: 
Figura 7: Proposta de layout da Fábrica de Caldeiraria da Oficina de Manutenção de Vagões

Lado Esquerdo

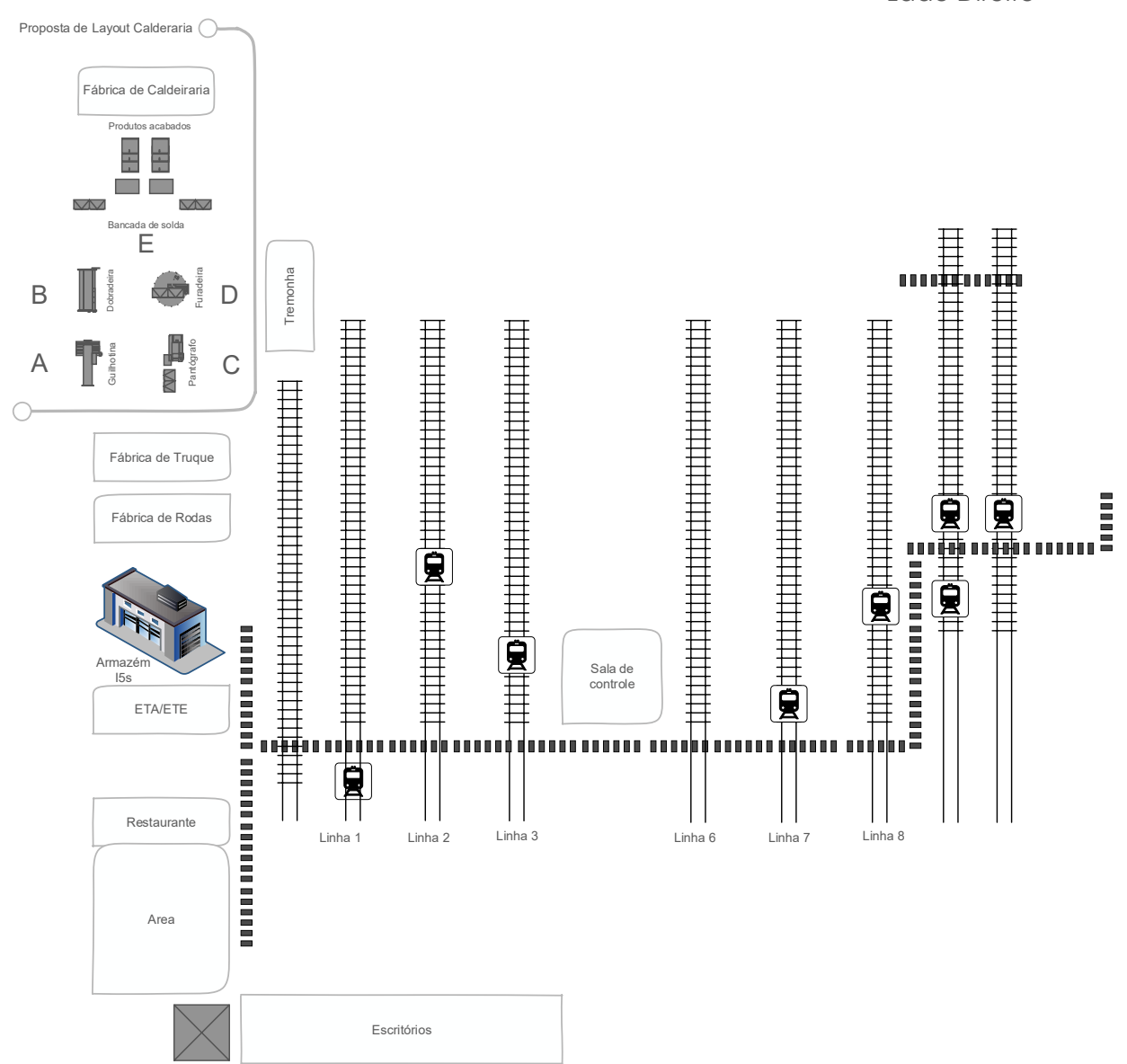

Fonte: Elaborado pelos autores
Lado Direito 
Figura 8: novo MFV da fábrica de Caldeiraria

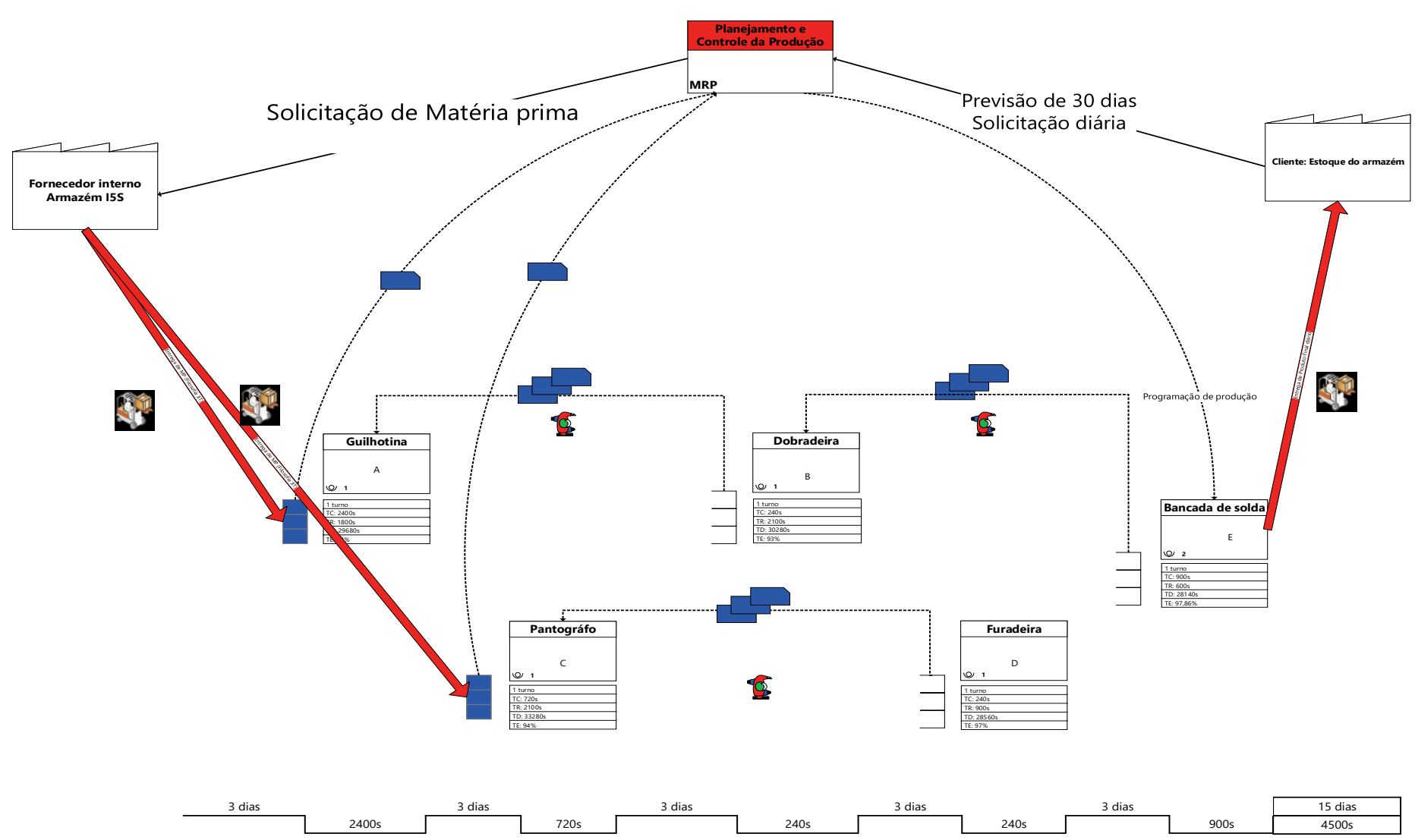

Fonte: Elaborado pelos autores 
Fica evidente que os fluxos e movimentações no MFV futuro tornaram - se mais organizados, possibilitando um aspecto mais limpo e definido. Buscou - se, inicialmente implementar a ideia de fluxo contínuo, com sinal de puxada para a próxima etapa, através da utilização de supermercados e kanban. A implementação do planejamento aliado ao fluxo de produção puxado faz com que o sistema seja unificado e cíclico. Portanto, o fluxo flui sem paradas, esperas ou filas, fazendo com que a remuneração pelo serviço venha mais rápido, com lead time menor.

O cliente da fábrica, que antes era a Oficina de Vagões, passou a ser o próprio almoxarifado. É ele quem controla o estoque de matéria prima e os produtos acabados. Sendo assim, a Oficina requisita as portas de vagões gôndola ao almoxarifado, e este através do seu método de gerenciamento de estoque, solicita a fabricação de produtos na fábrica de Caldeiraria. Todo o sistema passou a ser puxado.

Fez-se necessário um estudo de postos de trabalho onde foi verificada a redução de mão de obra em cada equipamento. Com as melhorias implementadas, um plano de manutenção foi realizado e o tempo de processamento reduzido.

A filosofia JIT foi implementada e a matéria prima chega no momento certo e na hora certa para abastecer o estoque de segurança das máquinas Guilhotina e Pantógrafo.

O quadro 2 apresenta três indicadores para comparação do MFV atual e futuro: lead time, o tempo de processamento e o número de postos de trabalho. É possível compreender as diferenças entre o estado atual e o estado futuro do MFV analisado, evidenciando as vantagens da aplicação dos princípios e das ferramentas da mentalidade enxuta do produto em estudo.

Quadro 2 - Indicadores comparativos entre MFV atual e futuro

\begin{tabular}{|c|c|c|c|c|}
\hline Estado & \multicolumn{4}{c|}{ MFV atual } \\
\hline MFV Futuro Redução & \% \\
\hline Lead Time & 49,64 & 15 & 34,64 & $70 \%$ \\
\hline Tempo de Processamento & 6040 & 4500 & 1540 & $25 \%$ \\
\hline Postos de trabalho & 10 & 5 & 5 & $50 \%$ \\
\hline
\end{tabular}

Fonte: Elaborado pelos autores

Com as melhorias implementadas, o lead time do processo de fabricação de portas de vagões gôndola, foi reduzido de 49,64 dias para 15 dias, representando $70 \%$ de diminuição, conforme pode ser visto na figura 9: 
Figura 9 - Comparação do Lead Time do MFV atual e futuro

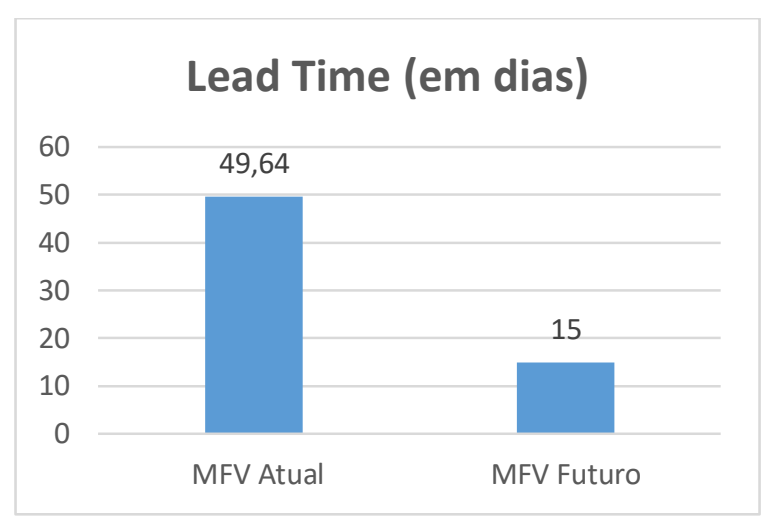

Fonte: Elaborado pelos autores

Já o tempo de processamento, como pode ser visto na figura 10 , foi comprimido de 6040 segundos para 4500 segundos, representando uma redução de $25 \%$.

Figura 10 - Comparação do Tempo de processamento do MFV atual e futuro

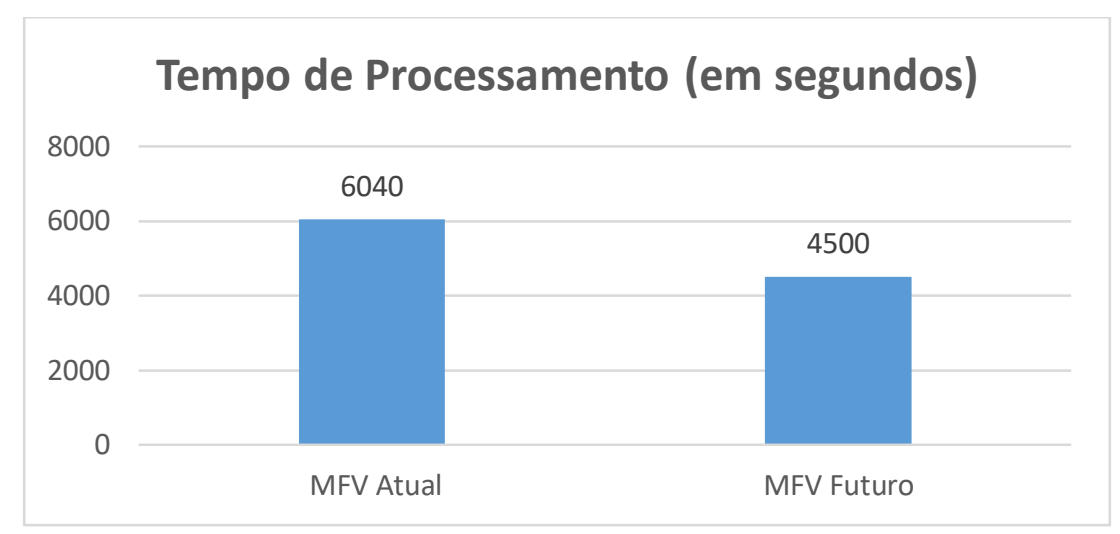

Fonte: Elaborado pelos autores

Quanto a quantidade de postos de trabalho, conforme pode ser visto na figura 11 , foi obtido uma redução de $50 \%$, passando de 10 postos para 5 postos de trabalho. Os colaboradores receberam convite para atuar em outras áreas da empresa que estavam necessitando de mão de obra. 
Figura 11 - Comparação dos postos de trabalho do MFV atual e futuro

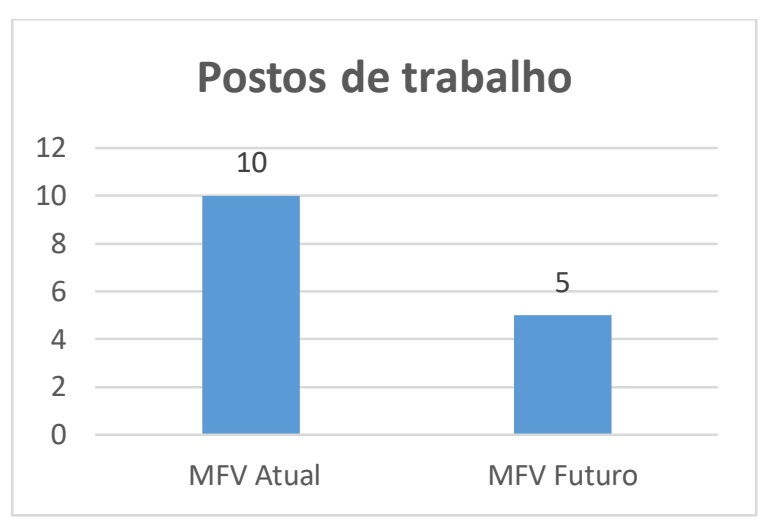

Fonte: Elaborado pelos autores

\section{CONCLUSÃO}

Este estudo de caso analisou o processo de produção de portas de vagões gôndola em uma Oficina de Manutenção de Vagões através dos conceitos de Lean Manufacturing e da ferramenta de Mapeamento do Fluxo de Valor (MFV). Assim sendo, a aplicação permitiu a identificação e a descrição dos desperdícios no processo, bem como a redução do lead time e do tempo de processamento do produto, aumentando a produtividade e elevando o nível de serviço para o cliente final.

Com o auxílio da ferramenta foi possível identificar as oportunidades de melhoria para idealizar e implementar um novo Layout, assim, obteve-se uma redução em $70 \%$ no Lead Time e em $25 \%$ no tempo de processamento.

Diante desses resultados, o Lean Manufacturing vai ao encontro das novas exigências do mercado, que busca otimizar os recursos existentes, de forma a atender o cliente no menor prazo, com alta qualidade e custos baixos. Em paralelo, a filosofia foca nas pessoas, que são elementos fundamentais para o sucesso, visto que são necessárias apenas boas ideias, de quem conhece o processo e tem o desejo de mudar para melhor. Nenhuma filosofia é implementada sem o empenho de todos da equipe desde o nível hierárquico mais alto ao mais baixo.

Portanto, o pensamento enxuto não é apenas um modelo de produção diferenciado dos tradicionais, sua implementação representa uma mudança geral na empresa, principalmente na cultura das pessoas. Sua implementação é algo que exige esforços múltiplos e toda organização precisa estar envolvida.

Tendo em vista os resultados alcançados no caso apresentado, recomenda-se que sejam feitos novos estudos e aplicações do MFV em outras indústrias, principalmente nos ganhos de redução do lead time e no tempo de processamento. 


\title{
Use of value flow mapping for the identification of waste in processes for production of wagons doors
}

\begin{abstract}
To make processes more efficient, productive and guarantee customer satisfaction, companies have adopted strategies that allow them to optimize their resources, making them more solid and competitive in the midst of several economic crises. Therefore, in the pursuit of these objectives and for its own survival, Lean Manufacturing has been implanted in organizational cultures. This philosophy has become a great differential in companies, since it consists of reducing and eliminating losses through activities that add value or not to the system. The objective of this work is to identify and describe the losses in the process of producing wagons, in a Wagon Maintenance Workshop, from the lean manufacturing tool: Value Stream Mapping (VSM). The methodological procedure consisted of a description of the production process of car doors wagons, from interviews with employees and observation of a workshop. After mapping the flow of value to the process, the generated losses were identified, and a new value stream with improvements for productivity increase was proposed. The results showed a significant improvement in the production process, with Lead Time reduction by $70 \%$ and processing time by $25 \%$. In view of these results, Lean Manufacturing meets the new requirements of the market, which seek to optimize existing resources, in order to serve the customer in the shortest time, with high quality and low costs. The study concludes that the implementation of the methodology provides real performance and financial gains for companies.
\end{abstract}

KEYWORDS: Lean Manufacturing. Value Stream Mapping. Elimination of losses. 


\section{REFERÊNCIAS}

ABDULMALEK, F.; RAJGOPAL J. Analyzing the benefits of lean manufacturing and value stream mapping via simulation: A process sector case study. International Jornal of Production Economics, Vol. 107, p. 226-239, 2007. crossref

CATAPAN, A. et al. Lean Manufacturing: um estudo de caso da sua aplicação em empresa do ramo de metais sanitários. Revista Científica da Escola de Gestão e Negócios. Natal. ano 3, n. 1, ago.2013/jan.2014. p.95-112. Disponível em: <https://repositorio.unp.br/index.php/connexio/article/view/514> Acesso em: 09 jul. 2018.

DENNIS, P. Produção Lean Simplificada. Um guia para entender o sistema de produção mais poderoso do mundo. Porto Alegre: Bookman, 2008.

GUTERRES, W. J. et al. Conceitos de lean manufacturing e aplicação de um sistema de gestão visual em uma indústria madeireira. Revista Tecnológica, v.6, no 1, p.59, 2017/1.

HANCOCK, D.; ALGOZZINE, B. Case study research: a practical guide for beginning researchers. New York: Teachers College Press,2006.

LEAN MANUFACTURING. Lean Institute Brasil. 2012. Disponível em: <http://www.lean.org.br/>. Acesso em: 25 dez. 2018.

MORAES, M. N. at al. Utilização do mapeamento do fluxo de valor para a identificação de desperdícios: estudo de caso em uma empresa de confecção. In: Encontro nacional de Engenharia de Produção, 31, 2011, Belo Horizonte, Artigo Cientifico, Minas Gerais: ENEGEP, 2011. P. 1-13.

OLIVEIRA, R. M. et al. A redução de desperdícios através do Kaizen: um estudo de caso em uma linha de montagem de jatos executivos. In: Congresso brasileiro de Engenharia de Produção, 5 .,2015, Ponta Grossa, Artigo Cientifico, Paraná: Conbepro, 2015. P.1-11.

PIRES, M. R. et al. A implantação do Lean Manufacturing em Pequenas Empresas. In: Semana internacional das engenharias da Fahor, 2.,2012, Rio Grande do Sul, Artigo Cientifico, Horizontina: Fahor, 2012. p.1-15.

RIANI, A. M. Estudo de Caso: O Lean Manufacturing Aplicado na Becton Dickinson. Monografia (Graduação em Engenharia de Produção) - Universidade Federal de Juiz de Fora, UFJF / Minas Gerais. 2006, 44 p.

RIBEIRO JUNIOR, H. J.; RODRIGUES, I. T. ; RIBEIRO, R. M. S. Proposta de aplicação de técnicas de produção enxuta para melhoria de layout em uma empresa de usinagem do sul de Minas. In: XXXII Encontro nacional de Engenharia de 
Produção. Artigo Cientifico. , 2012, Bento Gonçalves, Rio Grande do Sul: ENEGEP, 2012. p.2-14.

ROTHER, M.; SHOOK, J. Aprendendo a enxergar. Tradução de José Roberto Ferro e Telma Rodriguez. São Paulo: Lean Institute Brasil, 1999.

ROYER, R.; FERREIRA, A; SAVEDRA, A.L. Mapa Fluxo de Valor aplicado em uma micro cervejaria. Revista Gestão Industrial, Ponta Grossa, v. 14, n. 1, p. 01-18, jan./mar. 2018. crossref

RUIZ, L. L.; MENDES J.V.; SILVA, J.E.A.R. Análise da cadeia de suprimentos de uma empresa química utilizando mapeamento de fluxo de valor. Revista Reuna, Belo Horizonte-mG, v.21, n.3, p. 73-96, Set. 2016. crossref

SALGADO, E. G.; MELLO, C. H. P.; SILVA, C. E. S. da.; OLIVEIRA, E. S.; ALMEIDA, D. A. Análise da aplicação do mapeamento do fluxo de valor na identificação de desperdícios do processo de desenvolvimento de produtos. Gestão \& Produção, São Carlos, v. 16, n. 3, jul./set. 2009.

crossref

TEIXEIRA, R. P. L; ELIAS, S. J. B.; TUBINO, D. F. Análise e Proposta de Melhoria do Processo Produtivo Através do Mapeamento do Fluxo de Valor. Anais do XXX Encontro Nacional de Engenharia de Produção, São Carlos, São Paulo, Brasil, 2010.

WOMACK, J. P; JONES, D.T; ROOS, D. A máquina que mudou o mundo. Elsevier: São Paulo, 2004.

Recebido: 10 Mar. 2019

Aprovado: 10 Set. 2019

DOI: 10.3895/gi.v15n3.9803

Como citar:

MANTOVANI, Keilane Nieiro; NASCIMENTO, Schleiden Pinheiro. Utilização do mapeamento do fluxo de valor para a identificação de desperdícios em processos de produção de portas de vagões gôndola. R. Gest. Industr., Ponta Grossa, v. 15, n. 3, p. 148-168, Jul./Set. 2019. Disponível em:

<http://periodicos.utfpr.edu.br/revistagi . Acesso em:

Correspondência:

Keilane Nieiro Mantovani

Av. Vitória , número 2220, Bairro Monte Belo, Vitória, Espírito Santo, Brasil.

Direito autoral: Este artigo está licenciado sob os termos da Licença Creative Commons-Atribuição 4.0

Internacional.

(c) (1) 